\section{A SOCIOLOGIA DO ESPORTE NA ARGENTINA: APONTAMENTOS PRELIMINARES ACERCA DA ESTRUTURAÇÃO DE UM SUBCAMPO ACADÊMICO-CIENTÍFICO}

\author{
SOCIOLOGY OF SPORT IN ARGENTINA: PRELIMINARY NOTES ABOUT \\ THE STRUCTURING OF AN ACADEMIC-SCIENTIFIC SUB-FIELD C
}

LA SOCIOLOGÍA DEL DEPORTE EN ARGENTINA: NOTAS PRELIMINARES SOBRE LA ESTRUCTURACIÓN DE UN SUBCAMPO ACADÉMICO-CIENTÍFICO C己

døi)' https://doi.org/10.22456/1982-8918.103290

\section{Letícia Cristina Lima Moraes*<letsmoraes96@gmail.com>}

iD Alejo Levoratti ${ }^{* *}<$ levoratti@gmail.com>

Wanderley Marchi Júnior* <wmarchijr@gmail.com>

\footnotetext{
*Universidade Federal do Paraná. Curitiba, PR, Brasil.

**Universidad Nacional de La Plata. La Plata, Argentina.
}

Recebido em: 22-05-2020 Aprovado em: 17-11-2020 Publicado em: 30-12-2020

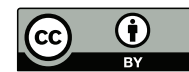

Este é um artigo publicado sob a licença Creative Commons Atribuição 4.0 Internacional (CC BY 4.0). eISSN: 1982-8918 


\section{INTRODUÇÃO}

Os sociólogos alemães Günter Lüschen e Kurt Hammerich apresentaram a Sociologia do Esporte como uma disciplina da Sociologia ${ }^{1}$ que ganhou força e representação quando, em 1964, foi fundado o Comitê Internacional para Sociologia do Esporte, em Genebra (LÜSCHEN; HAMMERICH, 1967). A inauguração do Comitê Internacional de Sociologia do Esporte (1964), que foi renomeado como International Sociology of Sport Association (INTERNATIONAL SOCIOLOGY OF SPORT ASSOCIATION,1965), e a criação da revista específica International Review the Sociology of Sport, em 1966, foram importantes marcos institucionais para a Sociologia do Esporte. Além disso, vale ressaltar a criação da North American Society for the Sociology of Sports (NASSS) em 1978, associação que publica o Sociology of Sport Journal (SSJ). As criações dessas instituições demarcam como esse subcampo do campo científico - compreendendo esse conceito baseado em Pierre Bourdieu (1975) como um microcosmo social estruturado e ocupado por agentes - começou a ganhar notoriedade no meio científico, concebendo gradualmente em seu interior leis e disputas próprias.

Entretanto, as tensões entre a Sociologia tradicional e aqueles que estavam realizando esforços em estudar um objeto que até então não recebia a devida ou postulada atenção sociológica, isto é, o esporte, sempre se mostraram presentes, independentemente do cenário (SEIPPEL, 2018). Gonzalez (1991) abordou essa apatia frente ao objeto por parte dos pesquisadores da Sociologia por considerarem o esporte e discussões associadas a ele como triviais e frívolas, deixando de lado a potencialidade reflexiva e problematizadora sobre sua interferência não somente no tempo livre, mas na economia, nas relações de poder, nos meios de comunicação, nas relações sociais, entre outros.

O sociólogo francês Pierre Bourdieu (1990, p. 207) apresenta uma outra perspectiva que é, no mínimo, provocante. O autor situa o ofício da Sociologia científica do esporte em dupla dominação: pelo universo sociológico e pelo universo do esporte, em que ao mesmo tempo é "desdenhada pelos sociólogos" e "desprezada pelos esportistas", formando, nesse caso, forças antagônicas e desfavoráveis para o desenvolvimento desse subcampo. Todavia, apesar desses embates e disputas, a Sociologia do Esporte apresenta-se atualmente como uma área do conhecimento estabilizada e que se expandiu para além das linhas territoriais citadas, apresentando a institucionalização no campo por meio de associações como a Korean Sociology of Sport Society (KSSS), a Japanese Sociology of Sport Society (JSSS) e a Asociación Latinoamericana de Estudios Socioculturalesdel Deporte (ALESDE).

A inserção desse subcampo de estudo no continente latino-americano teve seu início conturbado e às margens, conforme aponta Alabarces (2011), pois não existia bibliografia anterior, além do enfrentamento do descrédito atribuído àqueles que pesquisavam objetos esportivos baseando-se nas Ciências Sociais. Porém, conforme o mesmo autor, esse panorama vem se alterando gradualmente na América Latina ${ }^{2}$,

1 Dessa forma, iremos nos referir à Sociologia do Esporte como uma subdisciplina. Para saber mais sobre o desenvolvimento dos estudos na Sociologia do Esporte, ler Coakley e Dunning (2000)

2 Os estudos sociológicos do esporte têm sido fomentados por pesquisadores de diversificados países latinos- 
mostrando uma produção brasileira acentuada e reconhecida internacionalmente, seguida dos investimentos científicos e acadêmicos argentinos.

A análise da produção brasileira em Sociologia do Esporte já foi realizada por Ferreira $(2009 ; 2013 ; 2014)$. Ao final de seus trabalhos verificou-se, por exemplo, que os pesquisadores empenhados nesse tipo de pesquisa são predominantemente da área da Educação Física, não apresentando um grande número de sociólogos interessados no esporte. No entanto, no presente trabalho, abordaremos outro integrante envolvido em estudos sociológicos do esporte citado anteriormente: a Argentina.

Assim sendo, o presente ensaio tem o objetivo de apresentar um panorama da estrutura do campo científico argentino e localizar a Sociologia do Esporte no interior desse lócus, apontando as peculiaridades dessa subdisciplina na Argentina. As ponderações que serão expostas a seguir poderão contribuir como um tópico de pesquisa teórica para o entendimento do desenvolvimento da Sociologia do Esporte na Argentina, além de poder, possivelmente, constituir-se como uma peça para a análise da área na América Latina como um todo, visto que, conforme já foi apontado por Dart (2014), Tian e Wise (2019) e Gomes et al. (2020), pouco ou quase nada se sabe sobre os trabalhos da Sociologia do Esporte desenvolvidos nessa região. Para isso, a seguir, iremos apresentar primeiramente um panorama da constituição científica na Argentina e como a Sociologia do Esporte emergiu nesse cenário.

\section{O FAZER CIÊNCIA NA ARGENTINA}

Localizada no hemisfério sul ocidental, na América do Sul, com extensão territorial que consegue o título de oitavo país do mundo em superfície, a Argentina é o país que vai dos pampas aos Andes, ou de La Quiaca a Ushuaia ${ }^{3}$, e que, distribuídos geograficamente, possui três variações climáticas: o calor tropical no Chaco, clima temperado no Pampa e o frio subantártico na Patagônia (PALACIOS, 2013).

A Argentina faz fronteiras com o Chile, Bolívia, Paraguai, Uruguai e Brasil. Porém, essas demarcações territoriais muitas vezes se concretizam apenas no plano físico, principalmente quando se leva em consideração o desenvolvimento do cenário acadêmico do país. O intercâmbio de professores, programas de investigação e grupos de pesquisa são apontados pelo Centro Interuniversitario de Desarrollo Andino (CINDA, 1996) como primordiais para o desenvolvimento científico da Argentina. No estudo supracitado do CINDA, encontraram-se disparidades em relação ao desenvolvimento científico nos países analisados: Chile, Brasil e Argentina, sendo o último, na pesquisa publicada em 1996, o que dava passos mais lentos em direção à sua consolidação.

Para elucidar brevemente esse cenário, devemos ter em conta que desde os meados do século XIX, e com maior intensidade em 1885, momento em que as universidades passaram a ser nacionalizadas e os sistemas universitários passaram a ser regulamentados, a característica predominante do sistema universitário argentino

americanos, mas ainda está em processo de consolidação, apesar da evidente institucionalização ocorrida desde o início do século XXI (GOMES et al., 2020).

3 Esse termo se refere às duas cidades que estão localizadas nas extremidades boreal/setentrional e austral/ meridional na Argentina. 
era a de profissionalização, sendo sinal disso os investimentos nas formações de advogados, engenheiros e médicos (FREDERIC; GRACIANO; SOPRANO, 2010), influenciada pelo modelo napoleônico ${ }^{4}$ de formação superior. As instituições de ensino superior tinham o objetivo formar funcionários do Estado, ao mesmo tempo em que eram necessárias as titulações para o exercício de profissões liberais (BUCHBINDER, 2000).

Após o período da Segunda Guerra Mundial, para dar respostas à massificaçãoe à maior relevância atribuída ao conhecimento científico, os sistemas de ensino superior nos diferentes países da América Latina passaram por reformas através do modelo norte-americano (LOVISOLO, 1996; KROTCH, 2001). Isso implicou a diminuição do tempo dos cursos de graduação, promoção de pós-graduações, fomento de pesquisas e mudanças na modalidade de gestão institucional. Esse processo de modernização começou na Argentina a partir de 1956, principalmente na Universidade de Buenos Aires, com o financiamento de fundações norte-americanas (BUCHBINDER, 2005). Mesmo que algumas mudanças tenham sido efetivadas, a reforma foi fortemente criticada e resistida por diferentes atores da comunidade universitária local, pois ia de encontro ao caráter político estabelecido até então, além da oposição em relação ao financiamento e administração norte-americana e as influências ideológicas que isso poderia gerar (MOLLIS, 2003). Somadas a isso, devemos considerar também as intervenções dos governos militares nas universidades, alterando o funcionamento normal das instituições de ensino. Essas questões culminaram em uma estrutura formativa sem grandes modificações, perdurando os cursos de graduação de longo prazo e o processo de doutoramento sem uma organização curricular estruturada (BUCHBINDER, 2005).

Para auxiliar o processo de constituição de um sistema científico, foi criado em 1958, pelo Decreto Lei №. 1291, o Consejo Nacional de Investigaciones Cientificas y Técnicas (Conselho Nacional de Investigações Científicas e Técnicas/CONICET), para ser responsável pela promoção de ciência e tecnologia na Argentina. Objetivava-se com isso a organização e estruturação do organismo acadêmico no país. Entretanto, essa instituição não teve um funcionamento regular durante os períodos ditatoriais ${ }^{5}$ que assolaram o território (BENÍTEZ et al., 2016). De acordo com Garcia e Di Marco (2015), devido à influência dos "golpes de Estado" na Argentina, os programas de pós-graduação passaram a ser implementados nos anos 1960, porém com muitos traços de irregularidades e descontinuidades, podendo esses marcos históricos ser considerados um empecilho para o desenvolvimento científico argentino ${ }^{6}$.

Essas interferências da cúpula militar nas universidades se deram, segundo Bekerman (2010, p. 207), porque consideravam que essas instituições poderiam influenciar as mentes dos estudantes, formando uma "nova elite dirigente". Além disso, amparados pela teoria de uma segurança nacional, os militares argentinos viam a universidade como um espaço para promover ideias "subversivas" - uma das principais razões para a intervenção nesse espaço. Um exemplo das ações que

\footnotetext{
4 O modelo napoleônico primava pelo desenvolvimento da técnica, ciência e da tecnologia requerida pela Revolução Industrial, fundamentada nas necessidades práticas da classe dominante (SILVEIRA; BIANCHETTI, 2016).

5 A ditadura militar argentina ocorreu entre 1976-1983. Consultar Novaro e Palermo (2007).

6 O Brasil, diferentemente da Argentina, no período da ditatura militar teve um desenvolvimento crescente dos programas de pós-graduação (RODRIGUES FILHO, AGUILAR, 2016).
} 
ocorreram nesse período, logo após o golpe em 1976, segundo Bekerman (2010), foi a utilização de trâmites legais para que as universidades fossem controladas pelo Poder Executivo, a abolição dos setores administrativos do colegiado, atividades sindicais e políticas que existissem na universidade, além da demissão em massa de docentes e perseguição de estudantes.

Essa situação só se estabilizou com a redemocratização ocorrida a partir do ano de 1984, oferecendo às instituições universitárias um órgão que reorganizasse os estudos de pós-graduação, a SICUN (Sistema Universitário de Quarto Nível), em $1985^{7}$. Essa entidade pode ser considerada um dos pilares fundamentais identificados para a reorganização e fomento do campo acadêmico argentino, fornecendo uma pré-estrutura da organização do sistema científico, visto que os trâmites de regulamentação dessas atividades caminhavam lentamente no país. Entretanto, segundo o relatório publicado pelo Consejo Nacional de Investigaciones Cientificas y Técnicas (Conselho Nacional de Investigações Científicas e Técnicas/CONICET), na Argentina, em 1989, os programas de pós-graduação ainda não eram consolidados, tanto nas universidade públicas quanto nas particulares, demonstrando-se, portanto, como um cenário incipiente até aquele momento.

Foi somente a partir de 1990, segundo Rodrigues Filho e Aguilar (2016), que os programas de fomento e avaliação acadêmica tomaram real consistência quantitativa e qualitativa na Argentina. Em 1995 inaugurou-se o CONEAU ${ }^{8}$ (Comisión Nacional de Evaluación y Acreditación Universitarial Comissão Nacional de Avaliação e Acreditação Universitária), definindo padrões, condições e prazos para o reconhecimento desses sistemas universitários, com a missão de garantir qualidade do ensino superior e avaliar as carreiras universitárias. Ou seja, a premissa de um ensino mais qualificado poderia consolidar programas e linhas de pesquisa. Para gerenciar e avaliar esses programas, linhas e docentes dedicados à ciência e tecnologia, existia e existe o CONICET ${ }^{9}$.

De acordo com o site oficial ${ }^{10}$, atualmente o CONICET engloba mais de dez mil pesquisadores, oferecendo mais de 11 mil bolsistas de doutorado e pós-doutorado, além de comportar mais de 2.600 técnicos e profissionais de apoio às investigações. Os pesquisadores e demais envolvidos estão distribuídos em quatro grandes áreas de conhecimento: ciências agrárias, engenharia e de materiais; ciências biológicas e da saúde; ciências exatas e naturais; e a área de ciências sociais e humanas. Dentro dessas áreas estão contidas as disciplinas, onde a Educação Física e a Sociologia, por exemplo, pertencem à área de ciências sociais e humanas no CONICET.

O sistema de pós-graduação da Argentina possui as seguintes tipologias de títulos: especialização, mestrado e doutorado. O pós-doutorado, como no Brasil, não tem atribuição de titulação específica. Vale ressaltar que, para lecionar no ensino superior argentino, não se tem a obrigatoriedade de possuir algum grau de pós-

\footnotetext{
7 Essa iniciativa, segundo Benítez et al. (2016), não foi implementada efetivamente, mas definiu os diferentes níveis ou tipos de estudo - especialização, mestrado, doutorado, oferecendo uma estruturação básica e intencionando a organização do que chamam de "nível quartenário" de ensino.

8 O CONEAU e o CONICET, para fazer um paralelo, equivaleriam à Coordenação de Aperfeiçoamento de Pessoal de Nível Superior (Capes) e ao Conselho Nacional de Desenvolvimento Científico e Tecnológico (CNPq) no Brasil.

9 Os programas de pós-graduação argentinos são vinculados ao Ministério de Educação, mostrando que o Estado também está muito presente em sua estruturação.

10 Disponível em: https://www.conicet.gov.ar/conicet-descripcion/. Acesso em: 19 jan. 2020.
} 
graduação (RODRIGUES FILHO, AGUILAR, 2016), não gerando uma demanda tão grande como no sistema brasileiro, que está condicionado à titulação para adentrar nessas instituições, ampliando, consequentemente, o número de programas e pesquisadores do país. No entanto, no CONICET, é uma exigência para o ingresso como pesquisador o título de doutor.

Além dos aspectos apresentados, temos em conta que a partir do ano 1993 começou-se a implementar nas Universidades Nacionais o "Programa de Incentivos a los docentes-investigadores" (PI). Esta política pública procurava inscrever nas práticas de pesquisa os docentes universitários que não se encontravam inseridos no sistema científico do CONICET e na Agencia Nacional de Promoción de la Investigación, el Desarrollo Tecnológico y la Innovación ${ }^{11}$ (PRATI, 2009). O PI possibilitou, por vez, a primeira participação aos docentes de Educação Física nas práticas de investigação de modo institucionalizado, constituindo-se até hoje o principal marco institucional relacionado aos projetos científicos acreditados para a área (LEVORATTI; MACARIO, 2013).

Ademais, podemos dizer que o desenvolvimento do campo aconteceu continuamente, apesar de empecilhos, principalmente políticos. Assim, ele pôde se desenvolver de modo relativamente autônomo, seja através do vínculo com o CONICET, das pesquisas fomentadas nos programas de pós-graduação e/ou por meio de programas de incentivo aos docentes pesquisadores que estavam lotados em universidades. Essas instâncias e instituições apresentam um grau de relativa autonomia uma da outra, a qual é importante considerar ao nos reportarmos para os agentes e instituições.

Essa breve contextualização da formação do campo científico na Argentina dialoga com uma das condições anunciadas por Coakley e Dunning (2000) sobre a possibilidade de se inaugurar e se estabelecer uma área como a Sociologia do Esporte, pois foi só a partir da expansão do ensino superior e da carreira científica que esses estudos puderam ganhar traços mais consistentes no campo científico. Além do auxílio estatal para a conformação de estudos sociais e das humanidades, observamos nesse subcampo a influência de diferentes agentes para que pesquisas sobre o esporte, nesse viés, pudessem ser desenvolvidas em território argentino, conforme poderá ser melhor visualizado a seguir.

\section{A SOCIOLOGIA DO ESPORTE NA ARGENTINA: INFLUÊNCIAS, PRECURSORES E TENSÕES NO CAMPO CIENTÍFICO}

Partimos da premissa de que o campo dos estudos sociológicos sobre o esporte na América Latina se encontra institucionalizado. Contudo, a legitimação desses temas de estudos levou um longo processo, no qual podemos identificar os atores com diferentes enclaves institucionais. Os trabalhos do antropólogo Eduardo Archetti são considerados pelos pesquisadores argentinos o ponto de partida para a inauguração do campo desses estudos, principalmente o volume monográfico publicado pela Faculdade Latino-Americana de Ciências Sociais (FLACSO), em

11 É um órgão nacional, atuando na órbita do Ministério de Ciência, Tecnologia e Inovação. Tem o objetivo de promover a investigação científica na Argentina para aperfeiçoar o perfil produtivo e qualidade de vida da população. AAgência recebe projetos de pesquisadores, instituições e empresas (LAAGENCIA, 2020). 
1984, intitulado Fútbol y Ethos (ALABARCES, 2008; BRANZ; GARRIGA ZUCAL; MOREIRA, 2012; LEVORATTI; MOREIRA, 2016).

Embora o sociólogo e ensaísta Juan José Sebreli tenha publicado, em 1981, o livro Fútbol y masas, o autor o fez através de uma perspectiva crítica, buscando desacreditar a prática por sua ligação com o "populismo". Assim, mesmo com esses impulsos iniciais reconhecidos de Eduardo Archetti, foi apenas em 1994 que Pablo Alabarces apresentou no Instituto Gino Germani, da Universidade de Buenos Aires, o projeto de investigação "El fútbol como cultura: entre el juego y los medios masivos", implementado entre 1995 e 1997. Em 1996, na mesma instituição foram realizadas as primeiras jornadas nacionais "Deporte y ciencias sociales"12. Naquele mesmo ano Alabarces publicou com María Graciela Rodríguez o livro Cuestión de Pelotas. No ano de 1997 foi criada a Área Interdisciplinar de Estudos Esportivos na Faculdade de Filosofia e Letras da Universidade de Buenos Aires, um espaço no qual participaram psicólogos, sociólogos, historiadores, pedagogos e professores de Educação Física ${ }^{13}$.

Essas iniciativas isoladas consolidavam espaços de produção e discussão em nível local e regional. Contudo, o princípio da disseminação e institucionalização dos estudos do esporte, sob o viés sociológico na Argentina, foi principalmente através do Grupo de Trabalho Deporte y Sociedad, inaugurado em 1998 no Consejo Latinoamericano de Ciencias Sociales ${ }^{14}$ (CLACSO) sob a liderança de Pablo Alabarces (GUEDES, 2017). Esse grupo e suas publicações ${ }^{15}$, segundo Alabarces (2017), foram pontos centrais para a expansão desses estudos na Argentina e na América Latina, colaborando, novamente, para uma das circunstâncias que fortificou a Sociologia do Esporte no mundo científico, de acordo com Coakley e Dunning (2000): as publicações e a inauguração de instituições que englobam de forma específica essas discussões. Em adição, têm-se os esforços de professores universitários de Sociologia para evidenciar o esporte como prática social, devendo fazer parte da análise da sociedade e suas relações. Essas movimentações foram observadas a partir dos anos 1980 na Argentina.

Ainda, conforme Coakley e Dunning (2000), a alteração da percepção dos professores universitários de Educação Física em relação ao esporte, atribuindoIhe valor social, variáveis culturais e históricas, alterando os currículos de formação acadêmica que, predominantemente, pautavam-se em aspectos biológicos, foi uma das premissas para o avanço da subdisciplina de forma global. Esse processo na Argentina se realizou principalmente a partir de meados dos anos 1990, marcado pela sanção da Lei Federal de Educação no ano de 1993, gerando reformas realizadas em prol da formação dos professores de Educação Física.

Assim, na Argentina formou-se uma "sociología del deporte casi sin sociólogos". No entanto, com a presença de "sociólogos, antropólogos, historiadores, comunicólogos, profesores de educación física, filósofos, psicólogos" (ALABARCES,

\footnotetext{
12 Como resultado deste encontro publicou-se o livro Deporte y Sociedad, compilado por Pablo Alabarces, Roberto Di Giano e Julio Frydenberg (1998), o qual contou com o prólogo de Eduardo Archetti.

13 Um dos membros fundadores deste espaço foi o sociólogo Roberto Di Giano (2010), que trabalha sobre os usos políticos do esporte na Argentina.

14 Segundo Rodríguez (2013), uma reunião em Buenos Aires e em Lima, em 1997, foram as movimentações iniciais para o surgimento do grupo de trabalho na CLACSO.

15 As obras citadas pelo autor são: Peligro de Gol (2000) e Futbologías (2004).
} 
2017, p. 30). Esses aspectos formadores do subcampo sociológico do esporte na região, segundo Alabarces (2017), caracterizam-no como uma área interdisciplinar de fato. A participação de diferentes áreas e suportes teóricos constituíram o campo da Sociologia do Esporte desde o seu surgimento na América Latina através de esforços de agentes isolados em diferentes lugares. Todavia, essa heterogeneidade da área dificulta a angariação de autonomia e legitimidade dentro do campo científico, visto que disputas são travadas no campo científico em geral - buscando, por parte dos agentes e instituições, demonstrar quão relevante é o trabalho científico exercido nesse universo particular, e que está em constante alteração. Porém, cabe destacar que dentro da própria Sociologia do Esporte aconteciam e acontecem disputas entre aqueles que estão dispostos a falar do esporte sob o viés sociológico. No início essas discussões faziam parte de uma disputa de forças antagônicas, isto é, o debate do objeto esportivo através do viés sociológico era alheio tanto às ciências sociais quanto aos envolvidos na área esportiva/da Educação Física (BOURDIEU, 1990).

Alabarces (2004) ressalta que o esporte se tornou primeiramente objeto de discussão na imprensa, nos jornais e revistas, com discursos muitas vezes populistas e sem uma criticidade estabelecida, e só posteriormente passou a ser observado sob o crivo de estudiosos das ciências sociais e humanas, visto que na Argentina as discussões sobre o esporte na Educação Física só se estabeleceram no final do século XX.

A presença de jornais e revistas argentinas especializadas sobre o esporte é apontada por Alabarces (2004) como o princípio das tensões entre o discurso acadêmico iniciante e o solidificado discurso periodístico. Os jornais emergiram, de certa forma, concomitamente com as práticas esportivas, essas que ganharam, pouco a pouco, o espaço nas páginas dos jornais e revistas populares. Esse processo é demarcado desde a segunda metade do século XIX (OSMOND; PHILLIPS, 2009). Caracterizado por essa linguagem mais "popular", os setores acadêmicos das ciências sociais por muito tempo identificaram o esporte como um objeto irrelevante na Argentina, justamente por possuir esse vínculo com aspectos populistas e com o famigerado rótulo de "ópio do povo" (ALABARCES, 2004, p. 160).

De acordo com Jackson e Blanco (2014), quem ocupava o espaço de criticar e analisar a realidade social na Argentina, principalmente nos anos 1930, eram os ensaístas, geralmente publicando seus escritos em jornais. Dessa forma, os autores afirmam que os sociológos, nessa conjuntura, disputaram esse espaço através de seus textos publicados em veículos científicos (revistas, livros, etc.), trazendo à tona os discursos mais pragmáticos e eruditos, mas ainda sem a clara intenção de tratar do fenômeno esportivo, existindo, certamente, casos isolados que se ocuparam do assunto (PANZERI, 1967; 1974; ROMERO, 1985; 1986; 1994).

Além dessa disputa de lugar de fala entre os jornalistas, ensaístas e acadêmicos, também se fez presente outra problemática, mas agora, dentro do próprio meio científico-acadêmico argentino. Esse problema, segundo Alabarces (2004), é justamente por essa indefinição daqueles que deveriam/poderiam se apropriar e discutir sobre o esporte. Na Argentina, a formação de professores de Educação Física se realizou a partir de 1912 nos Institutos Nacionais de Educação Física, incorporando-se em 1953 o curso de gradução na Universidade Nacional 
de La Plata e na Universidade Nacional de Tucumán. Nesses espaços, a formação esteve direcionada preponderantemente na formação docente. A incorporação das práticas de investigação na disciplina, apesar de terem prevalecido o foco nas ciências sociais, estavam direcionadas aos estudos da identidade disciplinar, da didática e às problemáticas inerentes ao corpo, deixando as práticas esportivas como análises secundárias nesse meio. Observa-se, portanto, um cenário, até aqui, aberto para as discussões socioculturais do esporte na Argentina.

A ruptura dessa conjuntura de marginalização do objeto esportivo se dá, conforme sinaliza Alabarces (2004), com os estudos brasileiros, mais especificamente do antropólogo Roberto DaMatta, com a publicação de um compilado de textos sobre o esporte e sociedade em O universo do futebol (1982), além do clássico anterior Carnavais, malandros e heróis de 1979, introduzindo novos debates envolvendo o futebol. Entretanto, o papel impulsionador do Brasil esteve muito mais atrelado ao espaço de debate oferecido e as redes/trocas acadêmicas produzidas nesses âmbitos, desde os anos 2000, com a promoção de congressos - principalmente de antropologia - como os da Associação Brasileira de Antropogia (ABA), da Associação Nacional de Pós-Graduação e Pesquisa em Ciências Sociais (Anpocs) e na Reunião de Antropologia do Mercosul (RAM).

Com uma estruturação acadêmico-científica, esses temas muitas vezes marginalizados foram se introduzindo no cenário argentino pelos trabalhos do argentino Eduardo Archetti, a partir de 1984. Na Universidade de Buenos Aires, a área foi criando consistência com os estudos de Pablo Alabarces, María Graciela Rodriguez, e também com a institucionalização de grupos de trabalho como o "Deporte y Sociedade" da CLACSO e, posteriormente, com a fundação da Asociación Latinoamericana de Estudios Socioculturales del Deporte/ ALESDE, em 2007. A partir disso, novas publicações, teses, dissertações e linhas de investigação foram criadas, fortalecendo, pouco a pouco, as discussões socioculturais do esporte.

Para nos reportarmos especificamente ao contexto ou tentar ilustrar historicamente a ambiência que proporcionou o desenvolvimento da Sociologia do Esporte na Argentina, iremos nos reportar a dois personagens precursores desses estudos: Eduardo Archetti e Pablo Alabarces. O primeiro, tido para muitos, no caso argentino, como o pioneiro dos estudos antropológicos do esporte, mais especificamente do futebol, e é considerado como o propulsor para que outros estudos dessa linha fossem realizados (CADAA, 2016; ALABARCES, 2017; ALABARCES; GARRIGA ZUCAL, 2014). Além disso, os trabalhos de Archetti foram reconhecidos internacionalmente, principalmente por sua trajetória acadêmica ter migrado para a Noruega, fazendo esse intercâmbio e adquirindo o reconhecimento de seus escritos sobre esporte na/da Argentina e América Latina. Eduardo Archetti iniciou sua trajetória nos estudos sociais do futebol e esporte na década de 1980, abrindo, a partir daí, novas perspectivas para se pensar o esporte e os objetos das ciências sociais.

Archetti dedicou-se cientificamente às práticas sociais periféricas, mas emergentes na sociedade argentina, investindo inicialmente em estudos sobre o futebol, automobilismo, boxe e polo (ALABARCES; GARRIGA ZUCAL, 2014). 
Segundo Archetti (1994), a identidade nacional está intimamente relacionada às práticas sociais heterogêneas e, dentre elas, o esporte está incluso. No entanto, esse fenômeno costumava não chamar tanta a atenção de acadêmicos, sendo um objeto periférico no meio científico (DUNNING, 1999). Nesse sentido, Eduardo Archetti comparece nesse cenário como um "inventor de zonas nuevas para el trabajo académico", abrindo espaço para que outros estudos fossem realizados sobre esse objeto marginalizado (ALABARCES, 2008, p. 256).

Enquanto Pablo Alabarces, sociólogo argentino, nas palavras de Guedes (2017, p. 12), é o pesquisador cujos trabalhos também "avançaram fronteiras". Esse fato, marcado pela pesquisadora, é colocado justamente para evidenciar que desde o final da década de 1990, Alabarces já se constituía como um dos principais nomes dos estudos socioculturais do esporte. $\mathrm{O}$ autor produziu, inclusive, alguns trabalhos analisando o campo dos estudos sociais do esporte na América Latina e Argentina (ALABARCES, 2004; 2008; 2011; 2017), sempre tomando o cuidado para não fazer um relato autobiográfico devido a tamanha influência e participação que possui na área. Além disso, em 1996, Pablo Alabarces, juntamente com María Graciela Rodríguez, lançam o livro Cuestión de pelotas, considerado por Rodríguez (2013) como um marco inaugurador de novas discussões, pois foi realizada por agentes da academia local, e das ciências sociais, que sempre operou com debates críticos sobre a cultura e sociedade argentina. Essa obra, segundo luliano e Hang (2017), ainda é reconhecida como uma das primeiras a ter consistência e vitalidade em relação às produções especializadas sobre esporte no cenário argentino.

Assim, foi só a partir dos anos 2000, conforme aponta Raúl Cadaa (2016), que a Sociologia do Esporte entrou em processo de desenvolvimento, mas ainda necessita avançar alguns passos para realmente se consolidar no meio científico. Como visto anteriormente, a Sociologia do Esporte, para conseguir tomar traços mais consistentes, tem em seu interior a participação de saberes de diferentes áreas. Marchi Júnior, Almeida e Souza (2019) também salientam essa característica interdisciplinar da área da Sociologia do Esporte. Essa participação heterogênea produziu, até o momento, um acervo de materiais consistentes e extensos, principalmente quando se comparado ao final do século XX, ao qual Alabarces (2017) recorda que o corpo bibliográfico produzido até então não ultrapassaria uma prateleira da biblioteca.

Além da tensão entre/nas áreas dispostas a abordar o esporte envolvida nesses estudos, devemos evidenciar outro aspecto que compõe esse quadro. Em uma entrevista com Pablo Alabarces publicada na revista argentina Cuestiones de Sociología, realizada por Hang e luliano (2018), exploraram-se outros aspectos que influenciam o desenvolvimento da Sociologia do Esporte na Argentina até os dias atuais: em específico, o órgão de fomento e avaliação científica, o CONICET. Os entrevistadores contextualizaram a situação iniciada em 2016, com o corte de verbas para pesquisas consideradas "inúteis". Em resposta, Alabarces defendeu fortemente os estudos sociais do esporte, considerando essa ação da instituição como um retrocesso, visto que acompanhou o desenvolvimento científico em geral dentro do próprio CONICET. Ao analisar, através de um olhar histórico e de dentro dessa instituição, Alabarces ressaltou a falta de um planejamento adequado para 
administrar bolsas de estudos para a pós-graduação, colocando que entre 2004 e 2006 era mais fácil receber a bolsa do que perdê-la.

Essa conjuntura trouxe dois efeitos: a formação de muitos mestres e doutores e ascendeu (não só na Argentina) a cultura de "publish or perish"16, o que também desencadeou a produção de muitos artigos sobre o esporte a partir do início do século XXI. Essas produções, no entanto, cresceram quantitativamente, mas não necessariamente qualitativamente, o que Alabarces considera um dos "defeitos" desse sistema de cobrança pela produtividade. Nesse sentido, apoiando-se na noção de campo (BOURDIEU, 2004), podemos observar a influência que uma instituição (formada por agentes com interesses próprios) como o CONICET, ao deter maior capital econômico, um dos trunfos desse jogo específico, consegue regular as possibilidades daqueles que lutam com a desigualdade de distribuição de capitais (sejam eles econômicos, sociais ou culturais). Entretanto, devemos lembrar que os docentes que não se encontravam no sistema científico do CONICET, como era o caso da maioria daqueles pertencentes à Educação Física, puderam desenvolver práticas de investigação dentro do "Programa de Incentivo a los docentes-Investigadores" do Ministério de Educação da nação.

Por fim, ao verificar que, como uma subdisciplina que busca autonomia e ao depender de um órgão estatal (algo relativamente comum em todo o mundo), a dependência dessa instuição submete os agentes presentes nesse campo a um paradoxo já constatado por Bourdieu (2004): ao mesmo tempo que o fazer ciência encontra certa "liberdade" na sua produção quando se comparada àquelas que são realizadas em âmbito privado, os docentes e discentes dos programas de pós-graduação e programas de incentivo ficam subordinados às políticas vigentes dos governos que as subsidiam. Nessa perspectiva, os agentes estruturantes da Sociologia do Esporte na Argentina têm buscado além do capital científico (aliado ao capital simbólico baseado no reconhecimento e legitimidade), também o capital ecônomico para o possível desenvolvimento dos seus estudos e consolidação da área.

\section{CONSIDERAÇÕES FINAIS}

Ao intentar apresentar um panorama da estrutura do campo científico argentino e localizar a Sociologia do Esporte no interior desse lócus, identificaram-se neste estudo as características principais que regem o sistema científico da Argentina e as peculiaridades da Sociologia do Esporte que passaram a ser fomentadas dentro desse campo. Nesse sentido, observou-se que o campo científico argentino, após diversos obstáculos, principalmente políticos, se estruturou no país, seja através de órgãos nacionais que organizaram a pós-graduação, seja de instituições de fomento e incentivo à pesquisa. A criação de um sistema organizado de produção científica auxiliou no desenvolvimento das áreas e, dentre elas, a de estudos sociológicos do esporte.

16 "Publish or Perish"/Publique ou Pereça" é uma expressão criada para representar a pressão que os pesquisadores sofrem para publicar seus textos em revistas (e, principalmente, em periódicos com fator de impacto elevados). Para saber mais, ler Colquhon (2011). 
Uma das possíveis leituras do cenário da Sociologia do Esporte na Argentina é, primeiramente, que se trata de um campo de estudo recente, que iniciou nos anos 1980, através da iniciativa de pesquisadores da Antropologia e da Sociologia abordando, principalmente, o futebol. A partir disso, devemos considerar que os pesquisadores puderam encontrar um lugar para desenvolver seus estudos no grupo específico do CLACSO (criado e coordenado por Pablo Alabarces, demarcando uma institucionalização dessas pesquisas nos anos 1990), no CONICET, nos programas de pós-graduação das universidades e nos programas de incentivo à ciência como o PI.

Ademais, uma das características da Sociologia do Esporte argentina que podemos apontar, é o seu caráter interdisciplinar demarcado. A participação de sociólogos, antropólogos, historiadores, professores de Educação Física é notadamente presente desde o seu início, constituindo, assim, um subcampo plural, fomentado por diversas áreas de formação.

Assim, apesar do cenário conflituoso apresentado, seja a respeito da marginalização daqueles que se ocupam do fenômeno esportivo, seja da discussão acerca da relevância ou não dos estudos, considera-se que estamos diante de um campo repleto de possibilidades de análise, e em expansão. A Sociologia do Esporte da Argentina tem muito a contribuir com os trabalhos desenvolvidos até então e merecem a atenção dos pesquisadores brasileiros e internacionais, seja para mapear essa produção e assim conseguir informações essenciais para a compreensão do campo, ou para dialogar mais com aqueles que estão para além das nossas fronteiras geográficas.

O presente ensaio, por fim, traz à tona uma abordagem inicial dessa discussão - obviamente não a esgotando. Intentou-se contribuir com a elucidação, ou melhor, com a introdução desse cenário, localizando a Sociologia do Esporte nas dinâmicas científicas argentinas, ambicionando futuras produções embasadas em investigações empíricas que possam oferecer um panorama mais preciso da área na Argentina e, futuramente, na América Latina.

\section{REFERÊNCIAS}

LA AGENCIA. Ministerio de Ciencia, Tecnología e Innovación. Agencia Nacional de Promoción de la Investigación, el Desarrollo Tecnológico y la Innovación. 2020. Disponível em: https://www.argentina.gob.ar/ciencia/agencia/la-agencia. Acesso em: 14 maio 2020.

ALABARCES, Pablo. De la clandestinidade a la intervención pública: avatares de un campo. In: SOTO LAGOS, Rodrigo; FÉRNANDEZ VERGARA, Omar (comp.) ¿Quién raya la cancha?: visiones, tensiones y nuevas perspectivas en los estudios socioculturales del deporte en Latinoamérica. Buenos Aires: CLACSO, 2017. p. 25-38. 
ALABARCES, Pablo. Peligro de gol: Estudios sobre deporte y sociedad en América Latina. Buenos Aires: CLACSO-ASDI, 2000.

ALABARCES, Pablo. Veinte años de Ciencias Sociales y Deporte en América Latina: un balance, una agenda. Revista Brasileira de Informação Bibliográfica em Ciências Sociais, v. 58, p. 159-180, 2004.

ALABARCES, Pablo. Vinte anos de ciências sociais e esportes, dez anos depois. The Journal of the Latin American Socio-cultural Studies of Sport (ALESDE), v. 1, n. 1, p. 11-22, set. 2011.

ALABARCES, Pablo; DI GIANO, Roberto; FRYDENBERG, Julio. Deporte y Sociedad. Buenos Aires: Eudeba, 1998.

ALABARCES, Pablo; ZUCAL, José Garriga. Pionerismos, continuidades, deudas. Revista del Museo de Antropología, v. 7, n. 2, p. 327-330, 2014.

ARCHETTI, Eduardo. Fútbol y Ethos. Buenos Aires: FLACSO, 1984.

ARCHETTI, Eduardo. Masculinity and football: The formation of national identity in Argentina. In: GIULIANOTTI, Richard; WILLIAMS, John. Game without frontiers: football, identity and modernity, 1994. p. 225-243.

BEKERMAN, Fabiana. Modernización conservadora: la investigación científica durante el último gobierno militar en Argentina. In: BEIGEL, Fernanda. Autonomía y dependencia académica. Universidad e investigación científica en un circuito periférico: Chile y Argentina (1950-1980). Buenos Aires: Biblos, 2010, p. 207-232.

BENÍTEZ, Maria Cristaldo et al. Situación actual del posgrado en Argentina, Brasil y Paraguay: carreras, estudiantes e egresados. In: LAMFRI, Nora Zoila (coord.). Los posgrados en Argentina, Brasil y Paraguay: aproximaciones comparadas en contextos de avaluación de la calidad de la Educación Superior. Córdoba: Encuentro Grupo Editor, 2016.

BOURDIEU, Pierre. Programa para uma sociologia do esporte. In: BOURDIEU, Pierre. Coisas ditas. São Paulo: Brasiliense, 1990. p. 207-220.

BOURDIEU, Pierre. The specificity of the scientific field and the social conditions of the progress of reason. Social Science Information, v. 14, n. 6, 1975. p. 19-47. DOI:10.1177/053901847501400602. Disponível em: https://journals.sagepub.com/ doi/10.1177/053901847501400602. Acesso em: 12 dez. 2020.

BOURDIEU, Pierre. Os usos sociais da Ciência: por uma sociologia clínica do campo científico. São Paulo: UNESP, 2004.

BRANZ, Juan; GARRIGA ZUCAL, José; MOREIRA, Verónica. Deporte y ciencias sociales: claves para pensar las sociedades contemporáneas. La Plata: UNLP, 2012.

BUCHBINDER, Pablo. Historia de las universidades argentinas. Buenos Aires: Editorial Sudamericana, 2005.

BUCHBINDER, Pablo. El movimiento reformista de 1918: una aproximación desde la historia interna de las instituciones universitarias. Ibero-Amerikanisches Archiv, v. 26, $n$. 1-2, p.27-58, 2000.

CADAA, Raúl. Sociology of Sport: Argentina. In: YOUNG, K. Sociology of Sport: a global subdiscipline in review, v. 9, 2016. DOI: http://dx.doi.org/10.1108/S1476285420160000009027. Disponível em: https://www.emerald.com/insight/content/doi/10.1108/ S1476-285420160000009027/full/html. Acesso em: 12 dez. 2020. 
CINDA - CENTRO INTERUNIVERSITARIO DE DESARROLLO ANDINO. Programas de posgrado en Argentina, Brasil y Chile: caracteristicas y proyecciones. Santiago: Centro Interuniversitario de Desarrollo, 1996.

COAKLEY, Jay; DUNNING, Eric (ed.). Handbook of sports studies. London: Sage, 2000.

COLQUHOUN, David. Publish-or-perish: Peer review and the corruption of science. The Guardian, 2011. Disponível em: https://www.theguardian.com/science/2011/sep/05/publishperish-peer-review-science. Acesso em: 27 jan. 2020.

CONICET - CONSEJO NACIONAL DE INVESTIGACIONES CIENTIFICAS Y TÉCNICAS. Descripción. Disponível em: https://www.conicet.gov.ar/conicet-descripcion/. Acesso em: 08 dez. 2019.

DAMATTA, Roberto. Carnavais, malandros e heróis: para uma sociologia do dilema brasileiro. Rio de Janeiro: Rocco, 1979.

DAMATTA, Roberto. Universo do futebol: esporte e sociedade brasileira. Rio de Janeiro: Pinakotheke, 1982.

DART, Jon. Sports review: A content analysis of the International Review for the Sociology of Sport, the Journal of Sport and Social Issues and the Sociology of Sport Journal across 25 years. International Review for the Sociology of Sport, v. 49, n. 6, p. 645-668, 2014.

DI GIANO, Roberto. Futbol, Poder y discriminación social. Buenos Aires: Leviatán, 2010.

DUNNING, Eric. Sport matters: Sociological studies of sport, violence and civilisation. London: Routledge, 1999.

FERREIRA, Ana Letícia Padeski. O campo acadêmico-científico da sociologia do esporte no Brasil (1980-2010). 2014. 205 f. Tese (Doutorado em Sociologia) Departamento de Ciências Sociais, Universidade Federal do Paraná, Curitiba, 2014. Disponível em: https://acervodigital.ufpr.br/handle/1884/35877. Acesso em: 22 out. 2019.

FERREIRA, Ana Letícia Padeski. O estado da arte da sociologia do esporte no Brasil: um mapeamento da produção bibliográfica de 1997 a 2007. 2009. 269 f. Dissertação (Mestrado em Sociologia) - Departamento de Ciências Sociais, Universidade Federal do Paraná, Curitiba, 2009. Disponível em: https://acervodigital.ufpr.br/handle/1884/18362. Acesso em: 22 out. 2019.

FERREIRA, Ana Leticia Padeski et al. Notas sobre o campo da Sociologia do Esporte: o dilema da produção científica brasileira entre as Ciências Humanas e da Saúde. Movimento, v. 19, n. 2, p. 251-275, 2013.

FREDERIC, Sabina; GRACIANO, Osvaldo; SOPRANO, Germán. El Estado argentino y las profesiones liberales, académicas y armadas. Rosario: Prohistoria, 2010.

GARCIA, Lucía Beatriz; DI MARCO, María Cecília. El nivel de Postgrado en Argentina y Paraguay: hacia una matriz de comparación In: CONGRESO NACIONAL E INTERNACIONAL DE ESTUDIOS COMPARADOS EN EDUCACION, 5., Buenos Aires. Buenos Aires: Universidad de Buenos Aires, 2015. Disponível em: http://www.saece.com.ar/ docs/congreso5/trab023.pdf. Acesso em: 15 mar. 2020.

GOMES, Leonardo do Couto et al. A Mapping of JLASSS: The Academic Consolidation of the Socio-Cultural Studies of Sport in Latin America. International Review for the Sociology of Sport, p. $1-21,2020$. DOI: https://doi.org/10.1177/1012690219893658 
GONZÁLEZ, José Ignacio Barbero. Sociología del deporte: configuración de un campo. Revista de Educación, n. 295, p. 345-378, 1991.

GUEDES, Simoni Lahud. Prólogo: Redescobrindo a América. In: SOTO LAGOS, Rodrigo; VERGARA, Omar Fernandes. ¿Quién raya la cancha?: visiones, tensiones y nuevas perspectivas en los estudios socioculturales del deporte en latinoamérica. Buenos Aires: CLACSO, 2017. p. 11-17.

HANG, Julia; IULIANO, Rodolfo Martín. "Somos socios cadetes, todavía no nos pasaron a pleno": institucionalización y desafíos actuales del campo de Estudios Sociales del Deporte: entrevista a Pablo Alabarces. Cuestiones de sociología, n. 18, p. e060, 2018.

INTERNATIONAL SOCIOLOGY OF SPORT ASSOCIATION. General information, 2016. Disponível em: http://issa1965.org/about-issa/welcome-messagel. Acesso em: 15 mar. 2020.

IULIANO, Rodolfo; HANG, Julia. Dossier. Estudios sociales del deporte: un mapa local. [S.I.]: Programa Interuniversitario de Historia Política, out. 2017. Disponível em: http://www. historiapolitica.com/dossiers/dossier-estudios-sociales-del-deporte-un-mapa-local/. Acesso em 18 mar. 2020.

JACKSON, Luiz Carlos; BLANCO, Alejandro. Sociólogos e ensaístas no Brasil e na Argentina (1930 - 1970). In: MICELI, Sérgio; PONTES, Heloísa (orgs.). Cultura e Sociedade: Brasil e Argentina. São Paulo: EDUSP, 2014. p. 337-376.

KROTSCH, Pedro. Educación superior y reformas comparadas. Quilmes: Universidad Nacional de Quilmes, 2001.

LEVORATTI, Alejo; MACARIO, Paula. La lógica perversa y las exigencias académicas. Una aproximación a las perspectivas de los profesores en Educación Física de la Universidad Nacional de La Plata (UNLP) sobre el Programa de Incentivos a los DocentesInvestigadores. Revista Brasileira de Ciências do Esporte, v. 35, n.2, p.341-357, 2013.

LEVORATTI, Alejo; MOREIRA, Verónica. Deporte, Cultura y Sociedad. Buenos Aires: Teseo, 2016.

LOVISOLO, Hugo. Comunidades científicas y universidades en Argentina y Brasil. Redes. Revista de Estudios Sociales de la Ciencia, v. 3, n. 8, p. 47-94, 1996.

LÜSCHEN, Günter; HAMMERICH, Kurt. The Sociology of Sport. Current Sociology, v. 15, n. 3, p. 5-29, 1967.

MARCHI JÚNIOR, Wanderley; ALMEIDA, Barbara Schausteck; SOUZA, Juliano de. Introdução à Sociologia do Esporte. Curitiba: InterSaberes, 2019.

MOLLIS, Marcela. Un breve diagnóstico de las universidades argentinas: identidades alteradas. In: MOLLIS, Marcela. Las universidades en América Latina: ¿ reformadas o alteradas? La cosmética del poder financiero. Buenos Aires: CLACSO, 2003. p. 203-216.

NOVARO, Marcos; PALERMO, Vicente. A ditadura militar argentina 1976-1983: do golpe de Estado à Restauração democrática. São Paulo: EDUSP, 2007.

OSMOND, Gary; PHILLIPS, Murray. Sources. In: POPE, Steven Wayno; NAURIGHT, John (ed.). Routledge companion to sports history. London: Routledge, 2009. p. 34-50.

PALACIOS, Ariel. Os argentinos. São Paulo: Editora Contexto, 2013.

PANZERI, Dante. Fútbol, dinámica de lo impensado (1967); uno de los más influyentes en la historia futbolística del país. Buenos Aires: Paidós, 1967. 
PANZERI, Dante. Burguesía y gangsterismo en el deporte. Buenos Aires: Libera, 1974.

PRATI, Marcelo. El Programa de Incentivos y la "sociedad" universitaria. Revista

Pensamiento Universitario, v. 12, n. 12, p. 45-62, oct. 2009.

RODRIGUES FILHO, José Alberto; AGUILAR, Luis Enrique. Origem e desenvolvimento da pós-graduação na Argentina, Brasil e Paraguai. Ensaio Comparativo. In: LAMFRI, Nora Zoila (coord). Los prosgrados em Argentina, Brasil y Paraguai: Aproximaciones comparadas em contextos de evaluación de la calidad de la Educación Superior. Córdoba: Encontro Grupo Editor, 2016. p. 21-34.

RODRÍGUEZ, María Graciela. ¿Qué es un campo, y tú me lo preguntas? In: BRANZ, Juan; GARRIGA ZUCAL, José; MOREIRA, Verónica (comp.). Deporte y ciencias sociales.

Claves para pensar las sociedades contemporáneas. La Plata: EDULP, 2013. p. 337-362.

ROMERO, Amilcar. Las barras bravas y la contra sociedad deportiva. Buenos Aires: Centro Editor de América Latina, 1994.

ROMERO, Amilcar. Deporte, violencia y política (Crónica negra 1958-83).Buenos Aires: Centro Editor de América Latina, 1985.

ROMERO, Amilcar. Muerte en la cancha (1958-85). Buenos Aires: Editorial Nueva América, 1986.

SEIPPEL, Ørnulf. Topics and trends: 30 years of sociology of sport. European Journal for Sport and Society, v. 15, n. 3, p. 288-307, 2018.

SILVEIRA, Zuleide Simas da; BIANCHETTI, Lucídio. Universidade moderna: dos interesses do Estado-nação às conveniências do mercado. Revista brasileira de educação, v. 21, n. 64, p. 79-99, 2016.

TIAN, Enqing; WISE, Nicholas. An Atlantic divide? Mapping the knowledge domain of European and North American-based sociology of sport (2008-2018). International Review for the Sociology of Sport. DOI: 1012690219878370, 2019. Disponível em: https://journals. sagepub.com/doi/full/10.1177/1012690219878370. Acesso em: 12 dez. 2020. 
Abstract: Sociology of Sport emerged as a sub-discipline in the 1960s-70s in Europe and North America to analyze the interdependent relationship of the sporting phenomenon and life in society. Discussions on Sociology of Sport, however, only entered Latin American territory in the 1980s, mainly through anthropological studies on football in Brazil and later in Argentina. This essay outlines the structure of the Argentinean scientific field and locates Sociology of Sport within that system, pointing out the peculiarities of the subdiscipline in Argentina.

Keywords: Sociology. Sports. Argentina. History.

Resumen: La sociología del deporte, como una subdisciplina, surgió en los años 60-70 en Europa y América del Norte con el propósito de analizar la relación interdependiente del fenómeno deportivo y de la vida en la sociedad. Las discusiones sobre Sociología del Deporte, sin embargo, solo ingresaron al territorio latinoamericano a partir de la década de 1980, principalmente a través de estudios antropológicos del fútbol en Brasil y, más tarde, en Argentina. Este ensayo tiene como objetivo presentar una visión general de la estructura del campo científico argentino y localizar a la sociología del deporte en ese sistema, señalando las peculiaridades de esta subdisciplina en Argentina.

Palabras clave: Sociología. Deportes. Argentina. Historia. 


\section{LICENÇA DE USO}

Este é um artigo publicado em acesso aberto (Open Access) sob a licença Creative Commons Atribuição 4.0 Internacional (CC BY 4.0), que permite uso, distribuição e reprodução em qualquer meio, desde que o trabalho original seja corretamente citado. Mais informações em: http://creativecommons.org/licenses/by/4.0

\section{CONFLITO DE INTERESSES}

Os autores declararam que não há conflito de interesses neste trabalho.

\section{CONTRIBUIÇÕES AUTORAIS}

Letícia Cristina Lima Moraes: Escolha do objeto, delimitação da problemática, organização, inserção de referencial teórico relacionado ao texto, sistematização e escrita do texto.

Alejo Levoratti: Inserção de referencial teórico relacionado no texto, indicação de trabalhos já realizados, organização, sistematização e escrita do texto.

Wanderley Marchi Júnior: Inserção de referencial teórico relacionado no texto, delimitação do objetivo e problemática, organização, sistematização e escrita do texto.

\section{FINANCIAMENTO}

O presente trabalho foi realizado com apoio da Coordenação de Aperfeiçoamento de Pessoal de Nível Superior -Brasil (CAPES) - Código de Financiamento 001 This study was financed in part by the Coordenação de Aperfeiçoamento de Pessoal de Nível Superior - Brasil (CAPES) - Finance Code 001.

\section{COMO REFERENCIAR}

MORAES, Letícia Cristina Lima; LEVORATTI, Alejo; MARCHI JÚNIOR, Wanderley. A sociologia do esporte na Argentina: apontamentos preliminares acerca da estruturação de um subcampo acadêmico-científico. Movimento (Porto Alegre), v.26, p.e26097, jan./dez. 2020. Disponível em: https://seer.ufrgs.br/Movimento/ article/view/103290. Acesso em: [dia] [mês abreviado]. [ano]. DOI: https://doi. org/10.22456/1982-8918.103290

\section{RESPONSABILIBADE EDITORIAL}

Alex Branco Fraga*, Elisandro Schultz Wittizorecki, Ivone Job*, Mauro Myskiw*, Raquel da Silveira*

*Universidade Federal do Rio Grande do Sul, Escola de Educação Física, Fisioterapia e Dança, Porto Alegre, RS, Brasil 